\title{
Power system analysis of a resistive HTS fault current limiter
}

\author{
Jian X. Jin ${ }^{1 *}$, Zhen Y. Liu ${ }^{2}$, You G. Guo ${ }^{3}$, Jian G. Zhu ${ }^{3}$ \\ ${ }^{I}$ Centre of Applied Superconductivity and Electrical Engineering, University of Electronic Science and Technology of China, Chengdu 610054, China \\ ${ }^{2}$ School of Electrical Engineering and Telecommunications, University of NSW, Sydney, NSW 2052, Australia \\ ${ }^{3}$ Faculty of Engineering, University of Technology, Sydney, NSW 2007, Australia
}

\begin{abstract}
This paper investigates the performance of a prototype resistive fault current limiter (FCL) made using a high temperature superconductor (HTS). Its behavior under normal operation and short-circuit conditions in a $6 \mathrm{kV} / 1 \mathrm{kA}$ power system is analyzed with regard to the feasibility of using this HTS FCL device in electrical power systems. (C) 2001 Elsevier Science. All rights reserved
\end{abstract}

Keywords: High temperature superconductor; critical current; fault current limiter; fault current; electrical power system

\section{Introduction}

High temperature superconductors (HTS) based electrical fault current limiters (FCL) become viable technically and economically due to the development of HTS technology. There are various HTS FCL designs using different HTS materials [1,2]. This paper investigates the performance of a prototype resistive HTS FCL with normal and short-circuit operations in a test circuit through simulations. The feasibility of using this HTS FCL device in electrical power systems is analyzed. Results presented mainly include the power system fault current waveforms for the transient and steady states of the device.

\section{Basic prototype characteristics}

The principle of this HTS FCL device is to make use of the variation of the HTS resistance in different current stages. As the scaled I-V curve shown in Fig. 1, the resistance variation is represented by the gradient of the curve with the designed quench current for this case is about $1.5 \mathrm{kA}$ corresponding to the maximum rated system current.

The resistance is significantly increased if the current is over the quenching point. This operating feature substantially reduces the energy loss during the normal operating condition and limit the fault current under shortcircuit situation. With HTS manufacture technology using different scale factors, the design and construction of new HTS devices to fit different fault levels is achievable.

The behaviour of HTS can be predicted using a model and a circuit simulator. The behavioural modelling is based on superconductor I-V characteristics and using a Bi-2223 HTS sample. The characteristics for dc transport current can be determined using a power law $\mathrm{V}=\mathrm{kI}^{\mathrm{n}}$. This equation can be rewritten as $\mathrm{V}=\mathrm{e}^{\text {lnk+nlnI }}$. In order to get the value of $n$, two points before and after the transition point on the $\mathrm{I}-\mathrm{V}$ curve are considered and assigned as $\left(\mathrm{I}_{\mathrm{m} 1}, \mathrm{~V}_{\mathrm{ml}}\right)$ and $\left(\mathrm{I}_{\mathrm{m} 2}, \mathrm{~V}_{\mathrm{m} 2}\right)$, where $\mathrm{V}_{\mathrm{ml}}=\mathrm{kI}_{\mathrm{m} 1}{ }^{\mathrm{n}}$ and $\mathrm{V}_{\mathrm{m} 2}=\mathrm{kI}_{\mathrm{m} 2}{ }^{\mathrm{n}}$. Assuming that $\mathrm{V}_{\mathrm{m} 2}=\alpha \mathrm{V}_{\mathrm{m} 1}$ at $\mathrm{I}_{\mathrm{m} 2}=\mathrm{I}_{\mathrm{m} 1}+\Delta \mathrm{I}_{\mathrm{m}}$, therefore $\mathrm{n}=$ $\operatorname{In} \alpha / \ln \left(\mathrm{I}_{\mathrm{m} 2} / \mathrm{I}_{\mathrm{m} 1}\right)$, and also $\operatorname{lnk}=\ln \mathrm{V}_{\mathrm{m} 1}-\mathrm{nlnI}_{\mathrm{m} 1}$. By choosing $\mathrm{I}_{\mathrm{ml}}=\mathrm{I}_{\mathrm{c}}$ and using $\mathrm{V}_{\mathrm{m} 1}=1 \mu \mathrm{Vcm}^{-1}$ HTS criterion, then lnk = $-n \ln I_{c}, n=e^{\ln (\ln \alpha)-\ln [\ln (I c+\Delta I m)]}$, and $V=e^{n(\operatorname{lnI}-I n I c)}$. This equation can then be entered into a circuit simulator (e.g. Pspice) to predict the HTS I-V characteristic [3].

\section{Current limiting effect}

The layout of the designed test circuit as shown in Fig. 2 is a simplified $6.3 \mathrm{kV}$ system. Initially no HTS FCL is inserted into the circuit. The load is approximately 3.86 $\mathrm{kVA}$ with a power factor of 0.8 . The power line impedance is represented by the R-line and L-line with $0.030 \Omega$ and $0.546 \mathrm{mH}$. The shorted circuit is implemented by turning switch $\mathrm{K}$ on. 


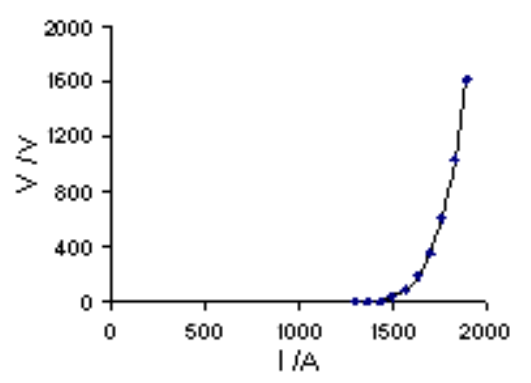

Fig. 1. The scaled HTS FCL I-V characteristic.

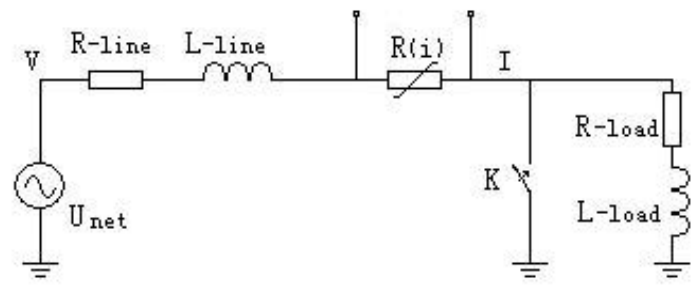

Fig. 2. Principle circuit with the HTS FCL.

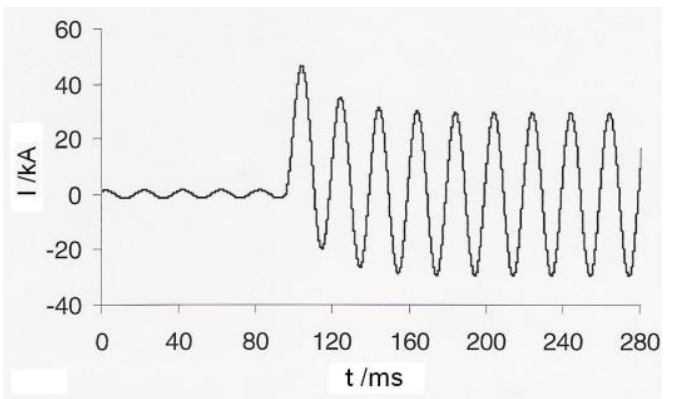

(a) Without the HTS FCL

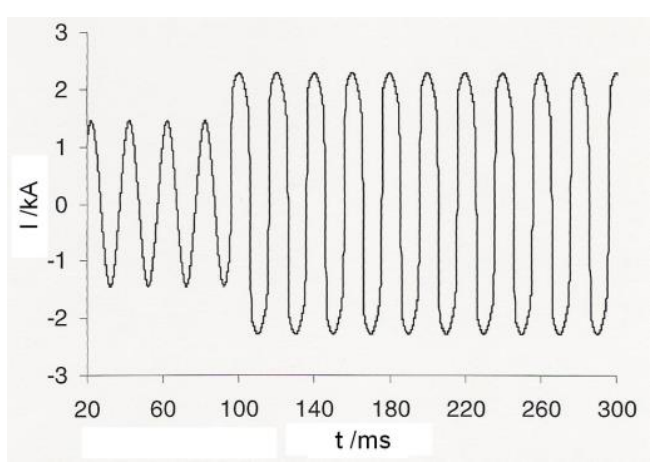

(b) With the HTS FCL

Fig. 3. Short-circuit current waveforms, (a) without the HTS FCL, (b) with the HTS FCL.

The line currents are shown in Fig. 3(a). At $95 \mathrm{~ms}$ the fault current suddenly soars to its peak of $46.47 \mathrm{kA}$ as the result of short circuit. The response time of a circuit breaker may be a few cycles. This huge fault current may flow through some network components, e.g. transformer, cable etc. The circuit breaker near the fault could be damaged in attempting to interrupt such high current. It is necessary to limit the high current in power systems to protect electrical equipments, and this can be achieved by using the HTS FCL as the result shown in the Fig. 3(b). Another advantage of this HTS FCL is its low energy loss in normal operation as shown in Fig. 4 [4].

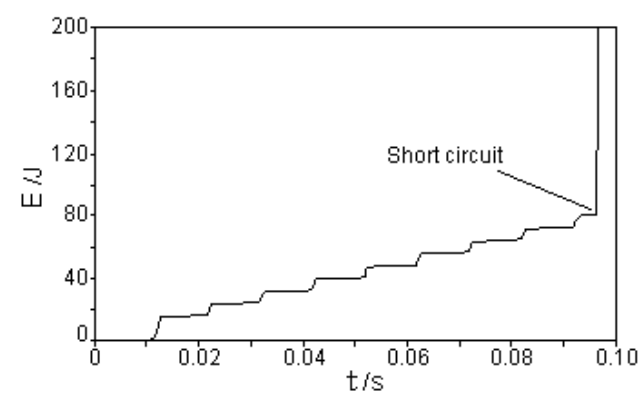

Fig. 4. Energy consumption on the HTS FCL in normal case.

\section{Summary and conclusion}

A non-linear resistive model was used to analyze the features of a resistive HTS FCL prototype with EMTP simulator. Its behavior under normal operation and shortcircuit conditions in a test circuit was investigated by computer simulation using the EMTP program. The results show that in the normal condition the voltage drop caused by this FCL is only about $0.1 \%$. The consumed electricity at $1 \mathrm{kA}$ rating is about $13.2 \mathrm{kWh}$ per day which is about $0.019 \%$ of transmitted energy. Waveform distortion due to the non-linearity of this prototype is also negligible. Under short-circuit conditions the fault current can be reduced by around 20 and 10 times for the transient and steady state respectively. This will significantly improve the working conditions of power equipments during a fault, especially reducing the stress on circuit-breakers. It could avoid the need to increase the fault level of existing switchgear in expanding power networks where the fault level has increased since the switchgear was originally installed.

\section{References}

[1] E.M.W. Leung, et al., Adv Cryog Eng. 42 (1996) 961.

[2] J.X. Jin, et al., Physica C. 341-348 (2000) 2621.

[3] J.X. Jin, et al., 24th Australian and New Zealand Inst. Physics Conf. / Annual Condensed Matter Physics Meeting, Wagga Wagga, Australia, 1-4 Feb., 2000, wp18.

[4] J.X. Jin, Z. Liu, C. Grantham, C. Sorrell, J.G. Zhu, Proc. Australasian Uni. Power Eng. Conf., Hobart, Australia, 25-28 Sept., 2005, 709. 